\title{
An Analysis of the Impact of Clean and Non-clean Energy Consumption on Economic Growth and Carbon Emission: Evidence from PIMC Countries
}

\section{Arshad Ali ( $\sim$ arshadswata@yahoo.com )}

QUT Business: Queensland University of Technology Business School https://orcid.org/0000-00034356-006X

\section{Magdalena Radulescu}

University of Pitesti: Universitatea din Pitesti

\section{Daniel Balsalobre Lorente}

University of Castilla-La Mancha: Universidad de Castilla-La Mancha

Viet-Ngu (Vincent) Hoang

QUT Business School: Queensland University of Technology Business School

\section{Research Article}

Keywords: Clean Energy Consumption, Carbon Dioxide Emission, Trade open, Economic Growth, PHH and EKC Hypothesis, PIMC Countries

Posted Date: January 14th, 2022

DOI: https://doi.org/10.21203/rs.3.rs-1103141/v1

License: (c) (1) This work is licensed under a Creative Commons Attribution 4.0 International License.

Read Full License

Version of Record: A version of this preprint was published at Environmental Science and Pollution Research on March 4th, 2022. See the published version at https://doi.org/10.1007/s11356-022-19284-x. 


\title{
An Analysis of the Impact of Clean and Non-clean Energy Consumption on Economic Growth and Carbon Emission: Evidence from PIMC Countries
}

\author{
Dr Arshad Ali ${ }^{1}$ \\ Postdoctoral research Scholar, Queensland University of Technology (QUT), Brisbane, Australia \\ arshadswata@yahoo.com \\ Magdalena Radulescu ${ }^{2}$ \\ Department of Finance, Accounting and Economics, University of Pitesti, 110040 Pitesti, Romania \\ Institute for Doctoral and Post-Doctoral Studies, University "Lucian Blaga" Sibiu, Bd. Victoriei, No. 10, \\ 550024 Sibiu, Romania \\ mag.radulescu@yahoo.com \\ Daniel Balsalobre Lorente ${ }^{3}$ \\ Department of Political Economy and Public Finance, Economics and Business Statistics and Economic Policy, \\ University of Castilla-La Mancha, 16002 Cuenca, Spain \\ Department of Applied Economics, International Economy Institute University of Alicante, 03690 San Vicente \\ del Raspeig, Spain \\ daniel.balsalobre@uclm.es
}

\author{
Associate Professor Viet-Ngu (Vincent) $\mathrm{Hoang}^{4}$ \\ | School of Economics and Finance | QUT Business School | CRICOS No. 00213J \\ Phone: +61731384325 | Email: vincent.hoang@qut.edu.au |
}

\begin{abstract}
This study empirically estimates the impact of clean and non-clean energy consumption on economic growth and carbon dioxide emissions within the framework of the environmental Kuznets curve and pollution haven hypothesis in the case of PIMC countries from 1980 to 2019. The results of the panel cointegration test proposed by Westerlund (2007) show a longterm equilibrium relationship among the variables of each designated model. The long-term elasticities of economic growth and carbon emission estimated by AMG, CCEMG and MG estimators indicate that both clean and non-clean energy consumption have a significant impact on economic growth, while carbon emission hinders growth. The results also reveal that economic growth, non-clean energy consumption and interaction between trade openness and non-clean energy consumption have a driving effect on carbon dioxide emission, however, clean energy consumption is found to reduce carbon emission. In addition, the analysis confirms the existence of the inverted U-shaped environmental Kuznets curve and pollution haven hypothesis in the panel of PIMC economies. Finally, there is a one-way causality from non-clean energy consumption to economic growth, but no such causation exists between clean energy consumption and economic growth. The objective of sustained economic growth with a safe environment may be achieved by encouraging clean energy consumption in the PIMC economies.
\end{abstract}

Keywords: Clean Energy Consumption, Carbon Dioxide Emission, Trade open, Economic Growth, PHH and EKC Hypothesis, PIMC Countries 


\section{Introduction}

Energy is an important spark of the world economy, a key functional factor for any country's economic growth, and a basic input for almost all goods and services in the new world (Ramezani et al., 2020; Stern, 2019; Ayres et al., 2013). In today's era every country mainly relies on energy at all stages of economic activities (from production to consumption). Thus, energy has become an important ingredient of industrialization and growth (Gong \& Razmjooy, 2020; World Economic Forum, 2012). However, in advanced, emerging, and developing economies, the widespread use of various energy sources increases carbon dioxide $\left(\mathrm{CO}_{2}\right)$ emissions and results in more residues and waste, thereby deteriorating the environment (Osobajo et al., 2020; Zou \& Zhang, 2020). China, Pakistan, India, and Malaysia (PIMC) are the panel of Asian developing economies, mainly focussed in this study. This is because the high dependence of these countries on non-renewable energy is the main driving force for higher growth, but it also leads to carbon dioxide emissions and environmental degradation (Khan, Khan \& Rehan, 2020). In 2019, the PIMC economies accounted for $17.81 \%$ of global GDP, $32.7 \%$ of world non-clean energy consumption and $38.2 \%$ of world carbon dioxide $\left(\mathrm{CO}_{2}\right)$ (World Bank, 2020). The global Gross Domestic Product (GDP) has grown significantly at an average annual growth rate of 2.9\% and has been doubled between 1992 and 2019. Meanwhile, world non-clean energy consumption has grown at an average annual rate of $2.0 \%$, from 8,223.6 million tons of oil equivalent (Mtoe) in 1992 to 1,3939.7 (Mtoe) in 2019 (World Bank, 2020). The large-scale combustion of energy (mainly traditional non-clean energy) has led to an excessive increase in global carbon dioxide $\left(\mathrm{CO}_{2}\right)$ emissions, from 21.354 billion tons $(\mathrm{Bt})$ in 1992 to 34.169 (Bt) in 2019 (Statistical Review of World Energy, 2020).

The protagonist of international trade believes that open trade can bring the latest technology, innovation and environmental improvement to developing countries, but the Pollution Haven Hypothesis (PHH) runs counter to the international trade picture of developing economies. PHH describes international trade as making developing economies a pollution haven for developed countries (López et al. 2013; Gani, 2013).

Consequently, clean energy is an emerging alternative to carbon-intensive fossil fuels and the most efficient energy source in the world. Considering the potential environmental threats identified by the environmental scientists and the resulting economic losses by economists, policymakers, and international organizations, the energy model needs to be transformed from non-clean energy to clean energy (Zhang, Xiao, \& Razmjooy, 2020). The identification of such potential threats has led to the growing global demand for clean energy to reduce carbon dioxide $\left(\mathrm{CO}_{2}\right)$ emissions and control the problem of global warming. The widespread use of clean energy ranges from the household sector (solar energy) to the industrial fields, filling in the availability, reliability, and affordability of energy between urban and rural areas. The generated non-carbohydrate energy will reduce the dependence on imported non-clean energy sources (such as oil, natural gas, coal, etc.), and will not emit carbon dioxide. Therefore, formulating a clean energy plan will improve the macroeconomic performance of the world economy.

Being a major contributor to carbon emission, the PIMC countries need to shift their economies from non-clean energy to clean energy to secure the whole world from havoc. The PIMC countries, therefore, need to invest sufficient funds in clean energy projects to overcome this problem. The study by Arroyo and Miguel (2020) also considers clean energy as a viable solution to the problems of energy security and climate change through the development of clean energy. In 2015, Malaysia's clean energy consumption accounted for 3.1\%, China's 5.3\%, India's 2.8\%, and Pakistan's $4.1 \%$ (World Bank, 2020). In response to the growing concern, The United Nations Climate Summit was held in New York on September 23, 2019. This summit was based on four needs: The goal was to make polluters pay and achieve zero net 
income by 2050, no new coal, and no fossil fuel subsidies. The growing concern at the international forums has attracted people's attention to the use of clean energy and is leading to the development of literature on the issue at hand. Therefore, the current study intends to four hypotheses to investigate the link between clean energy consumption and economic growth in the panel of PIMC countries. There is a one-way causal relationship between clean energy consumption and economic growth in the first growth hypothesis. Energy under this growth assumption plays an important positive role in economic growth. In this case, any energy-saving strategy will have an adverse effect on economic growth, and expansionary energy strategies will play a progressive role in economic growth. The second conservation hypothesis proposes a one-way causal relationship from economic growth to clean energy consumption. In this case, any drop in clean energy consumption will not adversely affect economic growth. In the third feedback hypothesis, a two-way causal relationship between clean energy consumption and economic growth is proposed. This connection speculates that the decline in clean energy consumption will hinder economic growth and vice versa. Finally, the neutrality hypothesis proposes of no causality between clean energy consumption and economic growth. Therefore, the decline of one factor will not affect another factor.

The studies confirm that increasing clean energy consumption can reduce global carbon dioxide emissions $\left(\mathrm{CO}_{2}\right)$. This may help create an Environmental Kuznets Curve (EKC) hypothesis between carbon dioxide and economic growth in PIMC countries. The hypothesis of the Environmental Kuznets Curve (EKC) postulates that economic growth will initially accumulate carbon dioxide $\left(\mathrm{CO}_{2}\right)$ and then decline when economic growth reaches a certain level (there is an unfavourable correlation between these two factors). More precisely, the economy of any country begins with industrial development to achieve higher growth goals. Therefore, a large number of natural resources (NR), especially energy, and the demand for large-scale combustion of energy in industrial development would lead to higher $\mathrm{CO}_{2}$ emissions. With the country's economic growth experience in industrialization, policymakers, governments, and people have begun to realize the use of clean energy, energy efficiency and environmental quality, thereby reducing carbon dioxide emissions. Hence, an inverted Ushaped link between carbon dioxide emission and economic growth is established. Therefore, the main purpose of this study is to investigate the link between clean energy and non-clean energy consumption and economic growth. Besides this, the study intends to assess the impact of clean energy on environmental degradation proxy by carbon dioxide emissions. Similarly, the study would test the hypothesis of the Environmental Kuznets Curve (EKC) and the Pollution Haven Hypothesis (PHH) in the case of PIMC economies.

\section{Literature Review}

Kuznets (1955) proposed the inverted U-shaped relationship between income inequality and economic growth and predicted that in the early stages of development, as social income (per capita income) increases, assuming that income inequality will increase. Still, beyond a certain income level, income Inequality will begin to decrease. This concept became popular in the name of the Kuznets curve. The official name is an inverted U-shaped curve. Kuznets received the Nobel Prize in 1971 in recognition of his work.

After Grossman and Kruger's pioneering work in 1991, recent environmental economists came up with this notion by hypothesizing the same inverted U shaped relationship between environmental degradation and income and named it Environmental Kuznets Curve (EKC).

The inverted U-shaped EKC hypothesis shows that the initial economic activities will cause environmental degradation, but the continued economic growth to a certain level can reverse the trend of environmental degradation and begin to improve environmental quality. Regarding 
150 the relationship between clean energy consumption, non-clean energy consumption, economic 151 growth, and carbon emissions, there are a large number of findings in the literature. Such 152 findings can be divided into two categories. The first category is related to single-country 153 research literature, mainly using econometric techniques of time series data. Joo, Kim, and Yoo relationship between clean energy, economic growth, globalization, and carbon dioxide relationship between clean energy, economic growth, globalization, and carbon dioxide emissions, covering the data range from 1965 to 2010. According to the research results, it is found that clean energy and carbon emissions are positively correlated with growth. Saliminezhad and Bahramian (2020) found that using the Standard sympatric framework covering the data range from 1965 to 2017, China's economic growth, clean energy consumption and carbon dioxide emissions have a long-term interdependence. This study further explored the adverse effects of clean energy on carbon dioxide emissions and the stimulus effect of clean energy on economic growth. Khan, Khan, and Rehan (2020) also pointed out that clean energy consumption, using Autoregressive Distributive Lag (ARDL), promotes Pakistan's economic growth and reduces the $\mathrm{CO}_{2}$ emission from 1965 to 2015. However, $\mathrm{Wu}$ (2019) adopted the linear and non-linear ARDL Bound test methods, covering the data range from 1960 to 2015, established the adverse effect of clean energy consumption on economic growth and the stimulus effect of non-clean energy consumption on economic growth. Sbia, Shahbaz, and Hamdi (2014) designated the UAE as a case study to discover the link between clean energy consumption and economic growth. The study used the ARDL method over the data range from 1975 to 2011. The study indicates that clean energy consumption can stimulate economic growth. Liu, Wang, Sun, Zhang, and Zhang (2020) used simultaneous equation modeling to determine the links between China's clean energy, haze pollution, and economic growth from 2006 to 2016. The results show that clean energy and haze pollution have significant adverse effects on economic growth. Haze pollution has a significant positive impact on clean energy and is negatively correlated with economic growth. In addition, the study recorded the stimulus effect of economic growth on clean energy and the adverse effect of economic growth on haze pollution. Sohag, Taskin, and Malik (2019) applied both the symmetric and asymmetric ARDL methods over the data range from 1980 to 2017 to determine the impact of clean energy, carbon emissions, and technological innovation on the growth of Turkey's green economy. The analysis reveals that carbon emissions have found to be detrimental to economic growth while clean energy and technological innovation are both the driving factors that promote the long-term growth of the green economy. Pata (2018) used three cointegration strategies: the ARDL Bound test, Gregory-Hansen, and Hatemi-J cointegration to discover the long-term relationship between economic growth, carbon dioxide, and renewable energy consumption in Turkey from 1974 to 2014. The cointegration test confirmed the long-term relationship, and the parameters' elasticities were tested with the Fully Modified Least Squares (FMOLS) test. The analysis indicates that economic growth gradually impacts $\mathrm{CO}_{2}$ emissions, while renewable energy has no impact on $\mathrm{CO}_{2}$ emissions. In addition, the analysis supports the existence of EKC in the context of Turkey. Bouznit and Romero (2016) used the ARDL method to examine the correlation between energy use, carbon dioxide emissions, and economic growth and tested the effectiveness of Algeria's EKC from 1970 to 2010. The results showed that the use of non-clean energy stimulated carbon dioxide emissions, while economic growth significantly hindered Algeria's carbon dioxide emissions. This has confirmed the validity of the EKC hypothesis in the case of the Algerian economy.

The second type of research literature involves the use of cross-sectional and panel data estimation procedures to examine the correlation between clean and non-clean energy consumption, economic growth, and $\mathrm{CO}_{2}$ emissions. The Bootstrap ARDL boundary check method used by Cai, Sam, and Zhang (2018) did not find a cointegration relationship between clean energy consumption, the real per capita GDP, and $\mathrm{CO}_{2}$ emissions in the United Kingdom, 
the United States, Italy, France, and Canada. However, a cointegration relationship was found in the context of Germany and Japan, in which per capita real GDP and $\mathrm{CO}_{2}$ emissions were included as dependent variables in the model. This study revealed that clean energy is positively correlated with per capita real GDP, but negatively connected with carbon dioxide emissions. Yao, Zhang, and Zhang (2019) used the panel cointegration method to determine the long-term relationship between energy consumption, renewable energy consumption, carbon dioxide and economic growth, and the effectiveness of EKC in a panel of 17 developed and developing economies over the data range from 1990 to2014. After determining the longterm cointegration relationship of the selected variables, the long-term elasticity of the coefficients estimated by the FMOLS method indicates that the impact of renewable energy and non-renewable energy consumption on economic growth is gradually significant. The consumption of renewable energy is found to have a significant negative impact on carbon dioxide emissions. Moreover, the analysis also confirmed the EKC hypothesis in the selected countries. Sharif, Raza, Ozturk, and Afshan (2019) also explored the reduction in $\mathrm{CO}_{2}$ emissions caused by the use of clean energy and the excessive $\mathrm{CO}_{2}$ emissions generated by the consumption of non-clean energy in 74 countries, covering the data span from 1990 to 2015. Fotourehchi (2017) study conducted the two-way causality test between clean energy and economic growth in 42 developing economies from 1990 to 2012. This study used the longterm causality test of Canning and Pedroni (2008) found a long-term causality from clean energy to GDP growth in the panel countries. Bhattacharya, Paramati, Ozturk, and Bhattacharya (2016) adopted the panel estimation techniques to investigate the relationship between clean energy consumption, non-clean energy consumption, carbon dioxide emissions, and economic growth in some38 countries having renewable energy sources. The long-term elasticity of the parameters indicates that clean energy consumption is harmful to greenhouse gases and significantly promotes economic growth. Boluk and Mert (2014) tested the validity of the EKC hypothesis in the panel data analysis of 16 euro countries, involving the correlation between carbon emissions, economic growth and energy consumption during the period 19902008. The results show no inverted U-shaped EKC hypothesis in euro countries. In addition, the results reveal that both non-clean energy and clean energy are harmful to carbon emissions in the case of euro countries.

230 In a nutshell, the literature reviewed so far clearly shows the mixed results of exploring the EKC and the link between energy consumption, economic growth, and carbon dioxide emissions. Thus, it's necessary to reveal further the connection between clean and non-clean energy consumption, economic growth and carbon dioxide emissions in a dynamic setting within the hypothetical framework of EKC and PHH, especially in the PIMC economies. Therefore, the current study claims to be the first to examine the links between clean and nonclean energy consumption, economic growth, and $\mathrm{CO}_{2}$ emission in the case of PIMC economies under the EKC and $\mathrm{PHH}$ hypothetical framework.

\section{3. Data and Methodology}

239 This study takes a panel of PIMC countries (i.e. Pakistan, India, China and Malaysia) to cover the data from 1980 to 2019. Clean energy consumption (CEC) data, expressed as a percentage of total energy use, non-clean energy consumption (NCEC) in million tons of oil equivalent (Mtoe), carbon dioxide $\left(\mathrm{CO}_{2}\right)$ emissions in million metric tons (Mmt), Trade openness (TOP) in percentage of GDP, Gross Domestic Product (GDP) and capital (K) are both in 2010 constant prices in U.S. dollars and the total labor force (L) in millions. The data were taken from the World Development Indicators (WDI) published by the World Bank on clean energy consumption, carbon emissions, non-clean energy consumption, capital formation, GDP, labor 
248 The main purpose of the study is to investigate the impact of clean and non-clean energy 249 consumption on economic growth and carbon dioxide emissions, and to verify the current 250 status of EKC and PHH in the case of PIMC economies. Thus, in order to ascertain the goal, 251 the following equations are proposed: $\operatorname{lnCO}_{2 \mathrm{it}}=\alpha_{0}+\alpha_{1} \operatorname{lnCEC}_{\mathrm{it}}+\alpha_{2} \operatorname{lnNCEC}_{\mathrm{it}}+\alpha_{3} \operatorname{lnGDP}_{\mathrm{it}}+\alpha_{4} \operatorname{lnGDP}_{\mathrm{it}}+\alpha_{5} \operatorname{lnTOP}_{\mathrm{it}} * \mathrm{NCEC}+\varepsilon_{\mathrm{it}}(2)$ Where GDP stands for Gross Domestic Product, CEC indicates clean energy consumption, $\mathrm{CO}_{2}$ shows carbon emission, and NCEC indicates Non-clean energy consumption. Further, L expresses labor force, GDP ${ }^{2}$ is the square of Gross Domestic Product, TOP displays trade openness and TOP*NCEC demonstrate the interaction between trade openness and non-clean energy consumption. $\beta_{0}$ and $\alpha_{0}$ are intercepts, $\beta$ and $\alpha$ are factor coefficients, $i$ is used for the country, $t$ is the time period. Similarly, $\mu \mathrm{i}$, $\alpha \mathrm{i}$ are the error terms. In order to verify the EKC hypothesis in the PIMC economies, GDP should be positively correlated with carbon dioxide $\left(\alpha_{3}>0\right)$, and the square of GDP must be negatively connected with carbon dioxide $\left(\alpha_{4}<0\right)$. And to validate the Pollution haven hypothesis $(\mathrm{PHH}), \mathrm{TOP} * \mathrm{NCEC}$ must have a positive influence on carbon emission $\left(\alpha_{5}>0\right)$. 


\subsection{Cross-section Dependence Test}

265 Due to the economic and social networks of exports, investment, economic and social integration, and imports, the interaction within the country dominates. This may lead to crosssectional dependence within the economies. In addition, model specifications and common shocks are other factors that cause cross-section dependence (Chudik \& Pesaran, 2013). If the cross-section dependence is not handled properly, the estimation results may be biased and inconsistent (Breusch \& Pagan, 1980; Pesaran, 2004; Phillips \& Sul, 2003). Hence, in panel data analysis, the detection of cross-sectional dependence becomes necessary. For this purpose, the general diagnostic test proposed by Pesaran (2004), which is the modified version of the LM test to adjust its biasness as follows:

$\mathrm{CD}=\sqrt{\frac{2 \mathrm{~T}}{N(N-1)}} \sum_{i=1}^{N-1} \sum_{J=i+1}^{N} \frac{(\mathrm{T}-k) \hat{\mathrm{A}}_{i j}^{2}-E\left[(\mathrm{~T}-k) \hat{\mathrm{A}}_{i j}^{2}\right]}{\operatorname{Var}\left[(\mathrm{T}-k) \hat{\mathrm{A}}_{i j}^{2}\right]}$

275 T indicates time trend, $\mathrm{N}$ shows total number of sample size, $\hat{\mathrm{A}}_{i j}^{2}$ denotes the pairwise 276 correlation for each country.

277 This test uses the correlation coefficient $\hat{\mathrm{A}}_{i j}^{2}$ between the time series of each panel country/region. The null hypothesis of this test assumes that panel variables have crosssectional independence, whereas the alternative hypothesis represents cross-sectional dependence. Accepting the null hypothesis confirms cross-sectional independence, and rejecting the null hypothesis indicates the existence of cross-countries dependence.

\subsection{Slope homogeneity test}

283 The slope heterogeneity may appear with cross-sectional dependence, and the countries in the panel data may influence each other in economic and social networks. Thus, in order to avoid unpredictable estimation, switching slope heterogeneity is very necessary (Breitung, 2005). Swamy (1970) proposed a combined estimator to reveal the heterogeneity of the slope by grasping the dispersion of the estimated individual regression coefficients. The slope homogeneity associated with the null hypothesis is tested against the slope heterogeneity of the alternative hypothesis. However, Pesaran and Yamagata (2008) performed a Swamy (1970) test on large panel data to check the homogeneity of the slope depicted in Equation (4):

$$
\bar{S}=\sum_{i=1}^{N}\left(\widehat{\beta} \iota-\bar{\beta}_{W F E}\right) \frac{\dot{X} M i X j}{\overline{\boldsymbol{\sigma}}_{i}^{2}}\left(\widehat{\beta} l-\bar{\beta}_{W F E}\right)
$$

$292 \hat{\beta}$ is the coefficient of each country in OLS regression, $\hat{\beta}_{W F E}$ represents the combined estimator

293 of weighted fixed effects, $\overline{\boldsymbol{\sigma}}_{i}^{2}$ is the estimator of $\sigma_{i}^{2}$ and Mt indicates identity matrix. The 294 following equations (5) and (6) are the formulas for the deviation adjusted dispersion $\bar{\Delta}_{A d j}$ and 295 the normalized dispersion statistic $(\overline{\boldsymbol{\Delta}})$, which employs $\operatorname{Var}\left(\bar{z}_{i t}\right)=\frac{2 k(T-K-1)}{T+1}$ and $\mathrm{E}\left(\bar{z}_{i t}\right)=\mathrm{K}$.

$$
\bar{\Delta}_{A d j}=\sqrt{N} \llbracket \frac{N^{-1} \tilde{S}-\mathrm{E}\left(\bar{z}_{i t}\right)}{\sqrt{\operatorname{Var}\left(\bar{z}_{i t}\right)}} \rrbracket
$$




\subsection{Checking of Panel Unit Roots}

300 After solving the main cross-sectional dependence or independence problem and detecting the slope heterogeneity in the panel variables, we continue to use the panel unit root test to check the stationarity level of each panel variable. Nonstationary time series data in econometric modeling may lead to spurious regression estimates (Dickey \& Fuller, 1981). Thus, understanding the level of stationarity in the sequence is the first step in any econometric exercise. Hence, this study first employed Pesaran (2007), the CIPS unit root test based on the hypothesis of cross-section dependence and slope heterogeneity in the panel variables. This test is also called the popular second-generation panel unit root test, which is specifically used for heterogeneity and cross-sectional dependence within panel variables. Later, we also used the panel unit root test of Levin et al. (2002) and Im et al. (2003), for this purpose. The following panel ADF process can be followed for the Levin et al. (2002) panel unit root test. $\Delta \mathrm{Y}_{\mathrm{i}, \mathrm{t}}=\kappa_{\mathrm{i}} \mathrm{Y}_{\mathrm{i}, \mathrm{t}-1}+\sum_{j=1}^{\kappa i} \Delta \mathrm{Yi}, \mathrm{t}+\mu_{\mathrm{i}, \mathrm{t}}$

According to Levine et al. (2002), it is assumed that the parameters $\kappa i$ are always mutual in the cross sections, that is, for all $\mathrm{i}, \kappa \mathrm{i}=\kappa$. Here $\Delta$ indicates the first-order differential, $\Delta \mathrm{Y}$ and $\Delta \mathrm{Yi}, \mathrm{t}-$ $\mathrm{j}$ have independent regression relationships with $\Delta y \mathrm{y}, \mathrm{t}-\mathrm{j}$ and residuals, and $\mathrm{j}$ represents the best time lag selected by SBC and AIC. The null hypothesis can be represented by $\mathrm{H}_{0}$ : $\rho \mathrm{i}=0$, which means that there is a unit root, where $\mathrm{H}_{1}: \rho \mathrm{i}<0$ is an alternative hypothesis, indicating that for all $i$ there is no unit root. The Im et al. (2003) unit root test has the same equation (7) as Levine et al. (2002), but it makes the cross-section of $\rho$ i uneven. The null hypothesis can be expressed as $\mathrm{H} 0$ : $\rho \mathrm{i}=0$, which means that all $\mathrm{i}$ have unit roots, and the alternative hypothesis can be stated as $\mathrm{H} 1$ : $\rho \mathrm{i}<0$, indicating that there are at least one or more unit roots of $\mathrm{i}$. Suppose it is found that the selected variables in the sequence are stationary at the first-order integration. In that case, it means that these variables are nonstationary at the level I( 0$)$ and become stationary when the first-order derivative I(1) is adopted.

\subsection{Test of Panel Cointegration}

Westerlund panel cointegration test will be the best choice for exploring long-term cointegration among panel variables with cross-sectional dependence and slope heterogeneity (Westerlund, 2007). This test can be used to detect the error correction $\left(\mu_{i}\right)$ of the entire panel and individual countries. The error correction $\left(\mu_{i}\right)$ represents the adjustment speed towards balance.

$$
\Delta Y_{i, t}=\dot{\delta}_{i} d_{t}+\mu_{i}\left(Y_{i, t-1}-\dot{\beta}_{i} X_{i, t-1}\right)+\sum_{j=1}^{p} \Omega_{i j} Y_{i, t-j}+\sum_{j=0}^{p} \Omega_{i j} X_{i, t-j}+\varepsilon_{i, t}
$$

331 The null hypothesis of no cointegration can be analyzed by using the Group mean test, $G_{a}$ and

$332 G_{t}$ statistics and the panel test, $P_{a}$ and $P_{t}$ statistics (Westerlund, 2007).

$333 \quad G_{t}=\frac{1}{N} \sum_{i=1}^{N} \frac{\mu_{i}}{\operatorname{Se}\left(\widehat{\mu}_{i}\right)}$

$334 \quad G_{a}=\frac{1}{N} \sum_{i=1}^{N} \frac{T \mu_{i}}{\mu_{i}}$

$P_{t}=\frac{\widehat{\mu}_{i}}{\operatorname{Se}\left(\widehat{\mu}_{i}\right)}$

$336 P_{a}=\mathrm{T} \hat{\mu}_{i}$

337 The cointegration of at least one cross-sectional country can be detected by using the statistics $G_{t}$ and $G_{a}$, and the statistics $P_{t}$ and $P_{a}$ can detect cointegration in the entire panel.

\subsection{Panel long-run estimates}

340 Cross-section dependence phenomena produces combined ordinary least squares (OLS) and feasible generalized least squares (GLS), leading to biased estimates (Phillips \& Sul, 2003). In addition, it avoids other common panel models, such as fixed effects (FE) and random effects (RE), from obtaining stable and consistent estimates (Sarafidis \& Robertson, 2009). The MG 
estimator first uses the OLS method to perform regression analysis on the time series of $\mathrm{N}$ countries, then averages the slope coefficients, and considers the heterogeneity of panel variables data when the coefficients and error variances vary from country to country (Pesaran $\&$ Smith, 1995). However, it prevents panel data for common factors.

348 The CCEMG estimator proposed by Pesaran (2006) is very robust in the presence of crosssectional dependence and slope heterogeneity in panel data, and captures undiscovered common effects (ft) (Kapetanios et al., 2011; Atasoy, 2017).

$Y_{i t}$ represents the dependent factor in Equation (13), $X_{i t}$ indicates explanatory factors, $\alpha_{i}$ shows intercept, $\beta_{i}$ represents the slope of the country, $f_{t}$ denotes unobserved and heterogeneous factors, and $\mu_{i t}$ indicates the error term. estimator to counter cross-section dependence and slope heterogeneity. AMG estimator controls the undiscovered common factor $f_{t}$ by using common dynamic effect parameters, which can be explained well. The AMG estimation formula is established in equation (15) and calculated by $\hat{\beta}_{i}$, where $\hat{\beta}_{i}$ is the estimated parameter of $\beta_{i}$ in Equation (15), which interpret the analysis of the first derivative data of OLS regression. $\kappa_{t}$ indicates the coefficient of time dummy $\mathrm{D}$ and $\Delta$ denotes difference operator in the equation (14).

Moreover, in the Monte Carlo simulation, the AMG estimator with $\mathrm{N}$ countries and $\mathrm{T}$ settings is unbiased and more effective (Bond \& Eberhardt, 2013). Hence, for the estimation of long run parameters, this study use Eberhardt and Teal (2010) AMG estimator. Robustness can also

\subsection{Granger's Panel Causality Test}

Lastly, the Granger panel causality test is used in the study to find the short-term bi-variate Granger causality among the selected variables. Thus for this purpose, the techniques recommended by Dumitrescu and Hurlin (2012), requires stationary data; hence the available data for all the factors in the study are stationary at first difference. Accounting for heterogeneity across countries is the unique nature of this test. The test is based on Granger non-causality using the average standard of Wald statistics derived from time series data. The following linear model illustrates the causal relationship between $\mathrm{Z}$ and $\mathrm{Y}$.

$$
\begin{aligned}
& \Delta \mathrm{Z}_{\mathrm{i}, \mathrm{t}}=\beta_{\mathrm{i}}+\sum_{n=1}^{n} \kappa_{\mathrm{i}}^{\mathrm{j}} \Delta \mathrm{Z}_{\mathrm{i}, \mathrm{t}-\mathrm{n}}+\sum_{n=1}^{n} \lambda_{\mathrm{i}}^{\mathrm{j}} \Delta \mathrm{Y}_{\mathrm{i}, \mathrm{t}-\mathrm{n}}+\mu_{\mathrm{i}, \mathrm{t}} \\
& \Delta \mathrm{Y}_{\mathrm{i}, \mathrm{t}}=\beta_{\mathrm{i}}+\sum_{n=1}^{n} \kappa_{\mathrm{i}}^{\mathrm{j}} \Delta \mathrm{Y}_{\mathrm{i}, \mathrm{t}-\mathrm{n}}+\sum_{n=1}^{n} \lambda_{\mathrm{i}}^{\mathrm{j}} \Delta \mathrm{Z}_{\mathrm{i}, \mathrm{t}-\mathrm{n}}+\mu_{\mathrm{i}, \mathrm{t}}
\end{aligned}
$$

Where $\Delta$ represents the first order differential, $\beta \mathrm{i}$ indicates lag parameter and $\kappa_{\mathrm{i}} \mathrm{j} \lambda_{\mathrm{i}}$ show lag coefficients. If any individual from the sample has an economic behaviour different from that of the others, then a uniform specification of the association between the variables $\mathrm{z}$ and $\mathrm{y}$ does not allow inferring the causality relationship (Dumitrescu \& Hurlin, 2012). In this case, the null hypothesis can be tested as $\mathrm{H}_{0}: \beta_{\mathrm{i}}=0,(\mathrm{i}=1, \ldots \mathrm{N})$, which reflects that the Granger causes of $Y_{i, t}$ and $Z_{i, t}$ are not homogeneous. Alternative hypotheses can be tested with $H_{0}: \beta_{i}=0$, (i = $1, \ldots \mathrm{K}_{1}$ ); $\mathrm{H}_{1}: \beta_{\mathrm{i}} \neq 0$, (for some cross-sections, $\mathrm{i}=\mathrm{K}_{1}+1, \mathrm{~K}_{1}+2, \ldots \mathrm{K}$ ), explains that $\mathrm{Y}_{\mathrm{i}, \mathrm{t}}$ is not the heterogeneous Granger cause of $\mathrm{Zi}$,t. More precisely, the null hypothesis of all cross-sections does not have homogeneous Granger causality, and for alternative hypotheses in some crosssections, there is at least one-way causality. The two subgroups in the cross-sectional alternative hypothesis are designated as causality from $\mathrm{Z}$ to $\mathrm{Y}$ in the first group, while no 
causality between $\mathrm{Z}$ and $\mathrm{Y}$ is detected from the second group. The average standard of Wald statistics can be used to specify each country's acceptance or rejection of the null hypothesis, which is expressed as:

$$
\mathrm{W}_{\mathrm{N} . \mathrm{T}}^{\mathrm{Hnc}}=\frac{1}{N} \sum_{i-1}^{N} W i, T
$$

Where $\mathrm{W}_{\mathrm{i}}$, T represents Wald statistics for each country/region.

400

401

402

403

404

405

406

407

408

409

410

411

412

413

414

415

416

417

\section{Empirical Analysis}

\subsection{Multicollinearity test}

When estimating the model concept of the EKC hypothesis, there is the possibility of multicollinearity, which is inadvertently ignored (Itkonen, 2012; p.277). Hence in order to solve this problem, we used centred values of each independent factor. The data for each variable must be recalculated by subtracting the mean to obtain the centred data. Such as we get the explanatory factors GDP-mean (GDP), L-mean (L), $\mathrm{CO}_{2}$-mean $\left(\mathrm{CO}_{2}\right)$, CEC- mean (CEC)... We used GDP ${ }^{2}$ as the square of GDP after centring in the model. Both VIF (variance inflation factor) and coefficient of determination have been used to check for multicollinearity in the centred and original data-independent factors. As shown in Table 1, serious multicollinearity problems have been encountered in the absence of data-centricity. The VIF value of each factor is very high, and $\mathrm{R}^{2}$ and $\mathrm{R}^{2}{ }_{5}>\mathrm{R}^{2}$, so the correlation matrix has a high correlation. However, after centring, the values of VIF are reduced to a certain extent, and the coefficient of determination, $\mathrm{R}^{2}$ of the entire model becomes higher than the other factors of $\mathrm{R}^{2}{ }_{1}, \mathrm{R}_{2}{ }_{2}, \mathrm{R}^{2}{ }_{3}, \ldots$. As a result, we used the centred data of the independent variables in the model by applying these diagnoses.

Table 1: Testing of Multicollinearity in the explanatory factors

\begin{tabular}{|c|c|c|c|c|c|c|c|c|c|c|}
\hline $\begin{array}{l}\text { Correlation } \\
\text { Matrix }\end{array}$ & & & & & & & & & VIF & $\begin{array}{l}\text { Coefficients of } \\
\text { determination }\end{array}$ \\
\hline \multicolumn{11}{|c|}{ Without centering } \\
\hline & InGDP & InGDP2 & $\operatorname{lnL}$ & InCO2 I & InCEC & InNCEC & $\operatorname{lnK}$ & InTOP*NCEC & \multirow[b]{2}{*}{152.43} & $R^{2}=0.98$ \\
\hline InGDP & 1 & & & & & & & & & $\mathrm{R}^{2}{ }_{1}=0.98$ \\
\hline $\operatorname{lnGDP}^{2}$ & 0.132 & 1 & & & & & & & 64.23 & $\mathrm{R}^{2}{ }_{2}=0.99$ \\
\hline $\operatorname{lnL}$ & 0.972 & 0.964 & 1 & & & & & & 75.34 & $\mathrm{R}^{2}{ }_{3}=0.98$ \\
\hline InCO2 & 0.721 & 0.218 & 0.243 & 1 & & & & & 39.64 & $\mathrm{R}^{2}{ }_{4}=0.97$ \\
\hline InCEC & 0.965 & 0.213 & 0.982 & 0.121 & 1 & & & & 45.86 & $\mathrm{R}^{2}{ }_{5}=0.99$ \\
\hline InNCEC & 0.324 & 0.167 & 0.131 & 0.134 & $4 \quad 0.132$ & 1 & & & 89.47 & $\mathrm{R}_{6}^{2}=0.97$ \\
\hline InK & 0.235 & 0.201 & 0.141 & 0.133 & $3 \quad 0.132$ & $2 \quad 0.103$ & 1 & & 93.73 & $\mathrm{R}^{2}{ }_{7}=0.97$ \\
\hline InTOP*NCEC & 0.943 & 0.315 & 0.651 & 0.452 & 20.14 & $3 \quad 0.134$ & 0.412 & 1 & 32.70 & $\mathrm{R}_{8}^{2}=0.98$ \\
\hline \multicolumn{11}{|c|}{ With Centering } \\
\hline \multirow[t]{2}{*}{$\begin{array}{l}\text { Correlation } \\
\text { Matrix } \\
\end{array}$} & & & & & & & & & $\begin{array}{l}\text { Co } \\
\text { de }\end{array}$ & $\begin{array}{l}\text { Coefficients of } \\
\text { letermination }\end{array}$ \\
\hline & InGDP & InGDP2 & $\operatorname{lnL}$ & $\mathrm{InCO} 2 \mathrm{I}$ & InCEC & InNCEC & $\operatorname{lnK}$ & InTOP*NCEC & & $\mathrm{R}^{2}=0.99$ \\
\hline InGDP & 1 & & & & & & & & 1.47 & $\mathrm{R}^{2}{ }_{1}=0.42$ \\
\hline $\operatorname{lnGDP}^{2}$ & 0.120 & 1 & & & & & & & 2.25 & $\mathrm{R}_{2}{ }_{2}=0.44$ \\
\hline $\ln \mathrm{L}$ & 0.922 & 0.921 & 1 & & & & & & 1.14 & $\mathrm{R}^{2}{ }_{3}=0.63$ \\
\hline InCO2 & 0.501 & 0.102 & 0.120 & 1 & & & & & 1.94 & $\mathrm{R}^{2}{ }_{4}=0.35$ \\
\hline InCEC & 0.142 & 0.123 & 0.342 & 0.031 & 1 & & & & 1.69 & $\mathrm{R}^{2}{ }_{5}=0.29$ \\
\hline InNCEC & 0.012 & 0.539 & 0.021 & 0.374 & 0.042 & 1 & & & 1.82 & $\mathrm{R}_{6}^{2}=0.52$ \\
\hline
\end{tabular}




\begin{tabular}{lllllllllll}
\hline InK & 0.105 & 0.304 & 0.031 & 0.153 & 0.012 & 0.153 & 1 & & 1.79 & $\mathrm{R}^{2}=0.39$ \\
InTOP*NCEC & 0.473 & 0.016 & 0.301 & 0.032 & 0.101 & 0.104 & 0.232 & 1 & 1.38 & $\mathrm{R}^{2}{ }_{8}=0.68$ \\
\hline
\end{tabular}

\section{$418 \quad 4.2$ Results of slope heterogeneity test}

419 The results of the slope heterogeneity test proposed by Pesaran and Yamagata (2008) are

420 shown in Table 2 . This test indicates that both the bias-adjusted statistics $\left(\bar{\Delta}_{A d j}\right)$ and the 421 statistics $(\bar{\Delta})$ are significant at the $1 \%$ significance level. Thus, it is concluded that the null 422 hypothesis related to slope homogeneity (no heterogeneity) is rejected, and the alternative 423 hypothesis that the panel data has slope heterogeneity is accepted.

$424 \quad$ Table 2: Test of slope heterogeneity

\begin{tabular}{|c|c|c|}
\hline Variables & $\bar{\Delta}$ & $\bar{\Delta}_{A d j}$ \\
\hline In GDP & $73.43 * * *$ & $152.75 * * *$ \\
\hline $\mathrm{InGDP}^{2}$ & $132.31 * * *$ & $327.43 * * *$ \\
\hline InL & $88.49 * * *$ & $284.37 * * *$ \\
\hline $\mathrm{InCO}_{2}$ & $135.32 * * *$ & $316.38 * * *$ \\
\hline InCEC & $257.93 * * *$ & $289.23 * * *$ \\
\hline InNCEC & $211.17 * * *$ & $142.23 * * *$ \\
\hline InK & $115.32 * * *$ & $214.53 * * *$ \\
\hline InTOP*NCEC & $274.28 * * *$ & $357.32 * * *$ \\
\hline
\end{tabular}

425

426

427

428

429

430

431

432

433

434

435

436

437

438

439

440

441

442

443

444

445

\subsection{Panel Estimation of Cross-sectional Dependence (CD) Test and Unit Root Tests}

For the estimation of panel cross-section dependence, this study used the Pesaran (2004) crosssectional dependence (CD) test to investigate dependency across countries, Table 3 lists the cross-sectional dependence (CD) test of panel variables such as GDP, GDP square, carbon dioxide emissions, clean energy consumption, non-clean energy consumption, capital formation, total labor force, and interaction of trade openness and non-clean energy consumption. The $\mathrm{CD}$ test strongly rejected cross-sectional independence of the null hypothesis at the significance level of 1 percent in all the panel variables. Hence it is concluded that there is cross-sectional dependence for all the variables. After confirming that the panel data have cross-sectional dependence and slope heterogeneity, therefore we use second-generation CIPS unit root tests (Pesaran, 2007) to investigate the stationarity of the variables. The result of CIPS unit root test is also established in Table 3. Later, for the same purpose, Levin, Lin, and James Chu (2002), Im, Pesaran, and Shin (2003) panel unit root tests were also used to reveal the order of integration of each panel variable. These tests assist in opt for appropriate empirical techniques for long term cointegration. The CIPS unit root test shows that these variables are nonstationary in the level but become stationary with the first-order derivative, so this means that all panel variables are integrated with the same order of I(1). Also in Table 4 below, the results of the LLC and IPS panel unit roots tests show the same findings as the CIPS test. These two tests show that all panel variables have unit roots at the level, but they are converted to stationary after taking the first derivative.

Table 3: Result of cross sectional dependence (CD) test and CIPS unit roots test

\begin{tabular}{lllllc}
\hline & \multicolumn{4}{l}{ Pesaran CD test } & \multicolumn{3}{l}{ Pesaran CIPS unit root test } \\
\hline Regressors & Statistics & Probability & Level & First difference & Decision \\
\hline InGDP & 11.311 & 0.000 & $-0.93(0.72)$ & $-3.28^{* * *}(0.000)$ & I(1) \\
\hline
\end{tabular}




\begin{tabular}{llllll}
\hline InGDP $^{2}$ & 41.101 & 0.000 & $2.20(0.92)$ & $-6.37 * * *(0.000)$ & $\mathrm{I}(1)$ \\
$\mathrm{InL}$ & 211.426 & 0.000 & $-1.26(0.53)$ & $-3.48 * * *(0.000)$ & $\mathrm{I}(1)$ \\
$\mathrm{InCO}_{2}$ & 39.267 & 0.000 & $1.15(0.79)$ & $-2.91 * * *(0.000)$ & $\mathrm{I}(1)$ \\
$\mathrm{InCEC}$ & 89.313 & 0.000 & $1.45(0.25)$ & $-3.07 * * *(0.000)$ & $\mathrm{I}(1)$ \\
$\mathrm{InNCEC}$ & 41.342 & 0.000 & $0.919(0.39)$ & $-2.162 * * *(0.000)$ & $\mathrm{I}(1)$ \\
$\mathrm{InK}$ & 57.123 & 0.000 & $-1.74(0.37)$ & $-4.020^{* * *}(0.000)$ & $\mathrm{I}(1)$ \\
InTOP*NCEC & 82.297 & 0.000 & $-1.261(0.61)$ & $-0.980^{* * *}(0.000)$ & $\mathrm{I}(1)$ \\
\hline
\end{tabular}

446

447

448

449

Note: :*** and $* *$ indicate significance levels of 1 and $5 \%$, respectively. The numbers in parentheses are the probability values.

Table 4: Result of Panel LLC and IPS unit roots test LLC test IPS test

\begin{tabular}{lllllr}
\hline Regressors & Level & First difference & Level & First difference & Decision \\
\hline InGDP & $1.09(0.80)$ & $4.12 * * *(0.000)$ & $1.17(0.80)$ & $4.09 * * *(0.000)$ & $\mathrm{I}(1)$ \\
InGDP $^{2}$ & $2.09(0.61)$ & $6.50^{* * *}(0.000)$ & $2.16(0.62)$ & $7.20^{* * *}(0.000)$ & $\mathrm{I}(1)$ \\
$\mathrm{InL}$ & $3.10^{* *}(0.03)$ & $8.46^{* * *}(0.000)$ & $3.29(0.13)$ & $8.68 * * *(0.000)$ & $\mathrm{I}(1)$ \\
$\mathrm{InCO}_{2}$ & $0.53(0.87)$ & $4.59 * * *(0.000)$ & $0.13(0.89)$ & $4.71 * * *(0.000)$ & $\mathrm{I}(1)$ \\
$\mathrm{InCEC}$ & $0.86(0.84)$ & $5.25 * * *(0.000)$ & $0.55(0.85)$ & $5.02 * * *(0.000)$ & $\mathrm{I}(1)$ \\
InNCEC & $0.006(0.91)$ & $5.194 * * *(0.000)$ & $0.019(0.89)$ & $5.186^{* * *}(0.000)$ & $\mathrm{I}(1)$ \\
InK & $-2.67(0.31)$ & $-6.56^{* * *}(0.000)$ & $-2.76(0.17)$ & $-6.540^{* * *}(0.000)$ & $\mathrm{I}(1)$ \\
InTOP*NCEC & $-0.630(0.83)$ & $-0.571 * * *(0.000)$ & $-0.711(0.91)$ & $-0.720^{* * *}(0.000)$ & $\mathrm{I}(1)$
\end{tabular}

450 451

452

453

454

455

456

457

458

459

460

461

462

463

Note: : *** and $* *$ indicate significance levels of 1 and $5 \%$, respectively. The numbers in parentheses are the probability values.

\subsection{Result of Panel Cointegration Test}

Next, when slope heterogeneity and cross-sectional dependence appear in the panel data, and all variables are stable on the first-order integral, we use Westerlund (2007) cointegration test to examine long-term cointegration relationship among the selected variables. All the robust pvalues in Table 5 are significant at the $1 \%$ significance level. Thus, reject the null hypothesis of no-cointegration, and accept the alternative hypothesis that there is a cointegration relationship among GDP, total labor force, clean energy consumption and non-clean energy consumption, carbon emissions, and interaction of trade openness and non-clean energy consumption.

Table 5: Result of Westerlund (2007) panel cointegration test, InGDP=f (InCO 2 , InNCEC, InCEC, InL, InK)

\begin{tabular}{lllc}
\hline Statistics & Values & Z-Value & Robust P-value \\
\hline$G_{t}$ & $2.63^{* * *}$ & -6.122 & 0.000 \\
$G_{a}$ & $15.52^{* * *}$ & 3.980 & 0.009 \\
$P_{t}$ & $5.31^{* * *}$ & -5.981 & 0.000 \\
$P_{a}$ & $8.873^{* * *}$ & -4.213 & 0.003 \\
\hline
\end{tabular}


$\operatorname{InCO}_{2}=\mathbf{f}\left(\operatorname{InGDP}, \operatorname{InGDP}^{2}, \operatorname{InCEC}, \operatorname{InNCEC}, \operatorname{InTOP} * \mathrm{NCEC}\right)$

\begin{tabular}{llll}
\hline Statistics & Value & Z-Value & Robust P-Value \\
\hline$G_{t}$ & $9.31^{* * *}$ & -7.201 & 0.000 \\
$G_{a}$ & $2.56^{* * *}$ & 4.134 & 0.007 \\
$P_{t}$ & $11.3^{* * *}$ & 6.315 & 0.000 \\
$P_{a}$ & $3.81^{* * *}$ & -5.215 & 0.000 \\
\hline
\end{tabular}

Note: $* * *$ show the null hypothesis of no cointegration rejection at the significance levels of $1 \%$.

\subsection{Estimation of heterogeneous long run parameters through estimators of AMG,} 467 CCEMG and MG

468 The cointegration test did not prove the flexibility of the selected related factors, so this study 469 chose AMG (Eberhardt and Teal, 2010; Bond \& Eberhardt, 2013), MG (Pesaran and Smith, 470 1995) and CCEMG (Pesaran, 2006) estimators to examine the influence of the selected variables on the growth and carbon emission in the PIMC economies. These estimators can only be used when the panel data has slope heterogeneity and cross-sectional dependence. Moreover, AMG is the main estimator for finding long-term parameters, while other CCEMG and MG are used for robustness checks. Table 6 shows the long-term estimated heterogeneous parameters of the AMG, CCEMG, and MG estimators. Long-term estimation parameters based on economic growth ensure a $1 \%$ increase in non-clean energy consumption, clean energy consumption and capital accumulation, which have significant stimulating effects on economic growth by $1.532 \%, 1.481 \%$, and $0.341 \%$, respectively. However, the total labor force is not significant and carbon emissions have a significant adverse effect on growth. This empirical result is consistent with the results of studies conducted on Chile by Joo, Kim and Yoo (2015) and Piłatowska and Geise (2021) in three selected countries (France, Spain, and Sweden). Similarly, Obradović and Lojanica (2017) also found similar discoveries in Northeast European countries; Fotourehchi (2017) explored for developing countries in the world; Yao, Zhang and Zhang (2019) used 17 major developing and developed countries in the world countries, the results come from two panel data sets of 6 geo-economic regions; Awodumi and Adewuyi (2020) obtained the results by selecting the largest oil-producing economies in Africa.

Long-term estimation parameters based on carbon dioxide emissions show that for every $1 \%$ increase in non-clean energy consumption and the interaction between trade opening and nonclean energy consumption, carbon dioxide will surge by $1.515 \%$ and $0.125 \%$, respectively. Hence, the interactive term parameter clearly confirms that PIMC countries have become a pollution haven $(\mathrm{PHH})$ for developed countries. And for every $1 \%$ increase in clean energy consumption, carbon dioxide will shrink significantly by $0.214 \%$.

These results are in line with our expectations and reflect that clean energy can be regarded as the most effective alternative to other non-clean energy. In other words, the surge in clean energy consumption is battling carbon dioxide in the PIMC economies. This result is very consistent with Kahia, Jebli and Bellumi (2019) on the cross-border study of Middle East and North Africa countries; Piłatowska and Geise (2021) explored the same results in three selected countries (France, Spain and Sweden); Awodumi and Adewuyi (2020) found this result in Africa's largest oil-producing economies. Analysis shows that higher consumption of clean energy promotes economic growth and significantly reduces carbon dioxide emissions. Thus, governments and policymakers concerned about emerging market economies should prioritize higher clean energy consumption. The other variables GDP helps accelerate $\mathrm{CO}_{2}$ and the square of GDP reduces $\mathrm{CO}_{2}$ emission. This shows that there is an environmental Kuznets curve (EKC) hypothesis in the panels of these emerging countries. This means that carbon dioxide emissions initially showed an upward trend, but they eventually deteriorated as GDP expanded during that period. This result is closely consistent with the study of Rauf, Liu, Amin, Ozturk, Rehman, and Hafeez (2018) on the economies of the "Belt and Road" initiative, and the study on the 
509 Turkish economy by K1lavuz and Doğan (2021). Arouri, Youssef, M'henni, and Rault (2012)

510 also found the same result in the study of the countries of the Middle East and North Africa.

511

512 Table 6: Long-term heterogeneous parameter estimation based on AMG, CCEMG and

513 MG estimators. InGDP = f(InNCEC, InCEC, InCO $\left.{ }^{2}, \operatorname{InK}, \operatorname{InL}\right)$

\begin{tabular}{llcc}
\hline Regressers & AMG & CCEMG & MG \\
\hline InNCEC & $1.532 * * *(4.261)$ & $1.337 * * *(4.574)$ & $1.326 * * *(4.912)$ \\
InCEC & $1.481 * * *(5.319)$ & $1.782 * * *(5.394)$ & $1.759 * *(5.413)$ \\
InCO $_{2}$ & $-1.132 * * *(-8.323)$ & $-1.328 * * *(-8.401)$ & $-1.319 * * *(-8.41)$ \\
InK & $0.341 * * *(4.921)$ & $0.801 * * *(4.801)$ & $0.872 * * *(4.812)$ \\
InL & $-0.202 \quad(-0.921)$ & $-0.354 \quad(-0.391)$ & $-0.372 \quad(-0.382)$
\end{tabular}

$\mathrm{InCO}_{2}=\mathrm{f}\left(\mathrm{InGDP}, \mathrm{InGDP}^{2}\right.$, InNCEC, InCEC, InTOP*NCEC)

\begin{tabular}{lccc}
\hline Regressers & AMG & CCEMG & MG \\
\hline InGDP & $0.203^{* * *}(4.31)$ & $0.391^{* * *}(4.309)$ & $0.421^{* * *(4.382)}$ \\
InGDP $^{2}$ & $-0.215^{* * *}(-4.01)$ & $-0.516^{* * *}(-4.094)$ & $-0.514 * *(-4.193)$ \\
InNCEC & $1.515^{* * *(6.235)}$ & $1.332^{* * *}(6.763)$ & $1.384 * * *(6.213)$ \\
InCEC & $-0.214^{* * *(-5.630)}$ & $-0.551 * * *(-5.596)$ & $-0.583 * * *(-5.629)$ \\
InTOP*NCEC & $0.125^{* * *(2.765)}$ & $0.465^{* * *}(2.842)$ & $0.495 * * *(2.738)$ \\
\hline
\end{tabular}

Note: ** and $* * *$ show significance levels of $10 \%$ and $1 \%$, respectively.

516

517

518

519

520

521

522

523

524

525

526

527

528

529

530

531

532

533

534

535

\subsection{Findings of Panel causality}

The empirical short-term two-way causality between the selected variables will be tested using the Dumitrescu and Hurlin (2012) panel causality test. The results are shown in Table 7, indicating that there is only a two-way causal relationship between $\mathrm{CO}_{2}$ and economic growth, while a one-way causal relationship exists from non-clean energy and clean energy to economic growth. Similarly, in the other variables of Equation 2, apart from non-clean energy consumption and $\mathrm{CO}_{2}$ emissions, we did not find any two-way causality, and there is one-way causality from $\mathrm{CO}_{2}$ to economic growth, from non-clean energy consumption to economic growth, from clean energy to economic growth, and from $\mathrm{CO}_{2}$ to the square of GDP. However, there is no evidence that there is a causal relationship between clean energy consumption and economic growth. It is now clear that with the opening of trade in dirty products with developed economies, non-clean energy consumption has played an important role in promoting economic growth, leading to a sharp increase in carbon dioxide emissions from PIMC economies. However, in view of concerns about climate change and greenhouse gas emissions, these emerging market economies should give priority to the use of clean energy and provide tax incentives for clean energy projects without affecting economic growth. The finding that there is one-way causal relationship from clean energy consumption to economic growth is consistent with the study of Fotourehchi (2017), Cai, Sam and Chang (2018).

Table 7: InGDP = f(InNCEC, InCEC, InCO2, InK, InL $)$

\begin{tabular}{|c|c|c|c|c|c|}
\hline Dependent & & & Independent $\mathrm{v}$ & ariables & \\
\hline $\begin{array}{l}\text { Variable } \\
\mathrm{InCO}_{2}\end{array}$ & InGDP & InK & $\mathrm{InL}$ & InCEC & InNCEC \\
\hline $\begin{array}{l}\text { InGDP } \\
2.123 * *(0.012)\end{array}$ & - & $0.897(0.753)$ & $1.921(0.891)$ & $2.134(0.023) * *$ & $1.841 * *(0.029)$ \\
\hline $\begin{array}{l}\text { LnNCEC } \\
0.524 * *(0.038)\end{array}$ & $0.987(0.786)$ & $0.874(0.451)$ & $0.964(0.132)$ & $0.567(0.423)$ & - \\
\hline $\begin{array}{l}\text { LnCEC } \\
0.021(0.121)\end{array}$ & $0.986(0.965)$ & $0.325(0.712)$ & $1.512(0.213)$ & - & $0.231(0.314)$ \\
\hline $\mathrm{LnCO}_{2}$ & $2.132(0.864)$ & $0.913(0.124)$ & $1.652(0.312)$ & $0.822(0.432)$ & $3.215^{* *}(0.032)$ \\
\hline
\end{tabular}




\begin{tabular}{lccccc}
\hline LnK & $1.534(0.913)$ & - & $0.341(0.315)$ & $1.301(0.614)$ & $1.013(0.152)$ \\
$0.142(0.314)$ & & & & & \\
LnL & $0.241(0.714)$ & $0.864(0.241)$ & - & $0.251(0.213)$ & $0.142(0.213)$ \\
$0.213(0.213)$ & & & & & \\
\hline
\end{tabular}

$536 \quad \operatorname{InCO}_{2}=\mathbf{f}\left(\right.$ InGDP, InGDP ${ }^{2}$, InNCEC, InCEC, InTOP*NCEC)

\begin{tabular}{|c|c|c|c|c|c|}
\hline \multirow{2}{*}{$\begin{array}{l}\text { Dependent } \\
\text { Variables } \\
\text { InGDP }\end{array}$} & \multicolumn{5}{|c|}{ Independent Variables } \\
\hline & $\mathrm{InCO}_{2}$ & $\mathrm{InGDP}^{2}$ & InTOP*NCEC & InCEC & InNCEC \\
\hline InGDP & $1.023 * *(0.021)$ & $0.362(0.813$ & $0.821(0.751)$ & $1.154(0.013)^{* *}$ & $1.081 * *(0.039)$ \\
\hline $\begin{array}{l}\text { InNCEC } \\
0.410(0.812\end{array}$ & $1.707 * *(0.010)$ & $0.761(0.520)$ & $0.823(0.202)$ & $0.664(0.513)$ & - \\
\hline $\begin{array}{l}\text { InCEC } \\
0.109(0.201)\end{array}$ & $0.613(0.805)$ & $0.403(0.802)$ & $0.410(0.303)$ & - & $0.320(0.401)$ \\
\hline $\begin{array}{l}\mathrm{InCO}_{2} \\
1.034(0.754)\end{array}$ & - & $0.812(0.214)$ & $1.422(0.402)$ & $0.902(0.512)$ & $2.105 * * *(0.004)$ \\
\hline $\begin{array}{l}\text { InGDP }^{2} \\
0.230(0.314)\end{array}$ & $1.410 * * *(0.003)$ & - & $0.210(0.405)$ & $0.106(0.504)$ & $0.313(0.282)$ \\
\hline $\begin{array}{l}\text { InTOP*NCEC } \\
0.213(0.213)\end{array}$ & $0.201(0.524)$ & $0.864(0.241)$ & - & $0.251(0.213)$ & $0.142(0.213)$ \\
\hline
\end{tabular}

537 Note: ** and $* * *$ show significance levels of $5 \%$ and $1 \%$, respectively.

\section{5. Conclusion and Policy Recommendations}

539 This study examines the impact of clean and unclean energy consumption, trade liberalization, 540 capital and labor on economic growth and carbon dioxide emissions, and tests the validity of 541 the EKC and PHH hypothesis in PIMC countries from 1980 to 2019.Two independent 542 specification models were developed in this research. The first model selects economic growth 543 as the dependent variable, and the second model uses carbon dioxide emissions as the 544 dependent factor. This study first tested the multicollinearity problem in the variables of each specified model. It then used the slope heterogeneity test proposed by Pesaran and Yamagata (2008) and the cross-sectional dependency test of Pesaran (2004). After confirming the slope heterogeneity and cross-sectional dependence of the panel data, this study continues to use Pesaran (2007) CIPS second-generation unit root test to reveal the smoothness of each panel data. In addition to other empirical studies on unit roots, Levin, Lin, and James Chu (2002), Im, Pesaran, and Shin (2003) are also used to check the level of stationarity of each selected factor. The Westerlund (2007) panel cointegration test is used to explore the long-term cointegration relationship within each specified model variable and to detect the long-term elasticity of economic growth and $\mathrm{CO} 2$ emissions, using AMG, CCEMG and MG estimators. Finally, for the short-term causality between selected variables, the panel causality test of Dumitrescu and Hurlin (2012) is applied.

Pesaran and Yamagata (2008) test found slope of heterogeneity and Pesaran (2004) CD test concluded cross-sectional dependence in the data of panel variables. Later Pesaran (2007) CIPS unit root test shows that all the variables are nonstationary in the level, but become stationary with the first-order derivative, so this means that all panel variables are integrated with the same order of I(1). Similarly, the results of the LLC and IPS panel unit roots tests show the same findings as the CIPS test. The findings of the Westerlund (2007) panel cointegration test indicate a long-term equilibrium correlation among the variables specified in Equation 1 and Equation 2. The long-term elasticities of economic growth and $\mathrm{CO}_{2}$ emission assessed by

564 AMG, CCEMG and MG estimators concluded that in the PIMC economies, non-clean energy consumption, clean energy consumption and capital have a significant gradual influence on economic growth. In contrast, $\mathrm{CO}_{2}$ emission has an adverse effect on economic growth. The research results also show that both economic growth, non-clean energy consumption and 
interaction of trade openness and non-clean energy consumption have a driving effect on $\mathrm{CO}_{2}$, but clean energy consumption has a negative impact on $\mathrm{CO}_{2}$ emission. In addition, the analysis confirmed the existence of the inverted $\mathrm{U}$ shaped EKC and PHH hypothesis in the panel of PIMC economies. Finally, there is a one-way causal relationship from non-clean energy consumption to economic growth. On the contrary, there is no causal relationship from economic growth to non-clean energy consumption. However, we did not find any causal relationship between clean energy consumption and the economic growth of PIMC economies Based on the above analysis, we can predict that higher economic growth brought about by trade liberalization and the use of non-clean energy consumption stimulate $\mathrm{CO} 2$, which indicates that these three parameters are the main triggers for $\mathrm{CO} 2$ in PIMC economies. Nonclean energy consumption makes $\mathrm{CO}_{2}$ soar, while clean energy consumption makes $\mathrm{CO}_{2}$ shrink, clearly indicating that clean energy consumption is a predictable element to slow down $\mathrm{CO}_{2}$ emissions. Here, it needs to be pointed out seriously that accelerating economic growth and non-clean energy consumption are of great significance to the merger of any emerging economy with an advanced economy. But clean energy consumption is a key driving force for reducing carbon dioxide emissions and the road to sustainable growth and a potential determinant of building a healthy environment. Thus, based on the results of this study, it is recommended that policymakers in PIMC countries prioritize the reduction of $\mathrm{CO} 2$ by stimulating the consumption of clean energy rather than non-clean energy to attain sustainable growth at the macro level. The important policy implications are based on the empirical analysis of this research. First, the impact of non-clean energy consumption and clean energy consumption on economic growth is gradually significant, but non-clean energy consumption stimulates $\mathrm{CO}_{2}$, and clean energy consumption significantly decreases $\mathrm{CO}_{2}$ emissions. Thus, policymakers in PIMC countries should give priority to the maturity of clean energy, which can not only meet energy needs but also reduce carbon dioxide emissions. Secondly, in order to promote and expand the development of clean energy in these emerging market countries, it is necessary to combine their respective professional knowledge and expertise, strengthen the guiding principles, and cooperate in research activities, development and demonstration. Third, the PIMC economies should attract domestic and foreign investment in clean energy projects, especially hydropower energy projects will be the best way to solve environmental problems. More importantly, in the production process of the PIMC economies, the high proportion of primary and secondary products exported to rich countries is based on the use of unclean energy. This higher productivity leads to higher carbon emissions and causes serious pollution to society and the environment. Thus, if decision-makers in exporting countries (in the PIMC economies) want to continue exporting products to rich countries, they must explore ways to invest and promote carbon emission reduction technologies in the production process to seek economic growth.

604

Availability of data and material: The data that support the findings of this study are openly available in World Development Indicator page published by (World Bank, 2020), at https://databank.worldbank.org/source/world-development-indicators.

610

Author contribution: A.A. (Ali) has contributed to idea conceptualization of the study, design, analysis, and conclusion; reviewed the edited manuscript; and approved the final submission. M.R. (Radulescu): supervision and conclusion, reviewed the edited manuscript, and approved submission. D.B.L. (Balsalobre-Lorente) conceptualized the study, software data curation, and literature search. V.V.H. (Hoang): review and editing. 
655

656

657

658

659

660

661

662

663

664

665

666

667

\section{Declarations}

Ethical approval: The study obtained ethical approval from Queensland University of Technology (QUT), Brisbane, Australia

Consent to participate: Not applicable.

Consent for publication: The authors have provided consent to publish this work.

Competing interests: The authors declare no competing interests.

\section{References}

Arroyo M, F. R., \& Miguel, L. J. (2020). The Role of Renewable Energies for the Sustainable Energy Governance and Environmental Policies for the Mitigation of Climate Change in Ecuador. Energies, 13(15), 3883.

Arouri, M. E. H., Youssef, A. B., M'henni, H., \& Rault, C. (2012). Energy consumption, economic growth and $\mathrm{CO} 2$ emissions in Middle East and North African countries. Energy policy, 45, 342-349.

Atasoy, B. S. (2017). Testing the environmental Kuznets curve hypothesis across the US: Evidence from panel mean group estimators. Renewable and Sustainable Energy Reviews, 77, 731-747.

Awodumi, O. B., \& Adewuyi, A. O. (2020). The role of non-renewable energy consumption in economic growth and carbon emission: Evidence from oil producing economies in Africa. Energy Strategy Reviews, 27, 100434.

Ayres, R. U., Van den Bergh, J. C., Lindenberger, D., \& Warr, B. (2013). The underestimated contribution of energy to economic growth. Structural Change and Economic Dynamics, 27, 79-88.

Bhattacharya, M., Paramati, S. R., Ozturk, I., \& Bhattacharya, S. (2016). The effect of renewable energy consumption on economic growth: Evidence from top 38 countries. Applied Energy, 162, 733-741.

Bölük, G., \& Mert, M. (2014). Fossil \& renewable energy consumption, GHGs (greenhouse gases) and economic growth: Evidence from a panel of EU (European Union) countries. Energy, 74, 439-446.

Bond, S., \& Eberhardt, M. (2013). Accounting for unobserved heterogeneity in panel time series models. University of Oxford, 1-11.

Bouznit, M., \& Pablo-Romero, M. D. P. (2016). CO2 emission and economic growth in Algeria. Energy Policy, 96, 93-104.

Breitung, J. (2005). A parametric approach to the estimation of cointegration vectors in panel data. Econometric Reviews, 24(2), 151-173. 
Breusch, T. S., \& Pagan, A. R. (1980). The Lagrange multiplier test and its applications to model specification in econometrics. The review of economic studies, 47(1), 239-253.

Cai, Y., Sam, C. Y., \& Chang, T. (2018). Nexus between clean energy consumption, economic growth and CO2 emissions. Journal of cleaner production, 182, 1001-1011.

Canning, D., Pedroni, P. (2008), Infrastructure, long-run economic growth and causality tests for cointegrated panels. The Manchester School,76, 504-527.

Chudik, A., \& Pesaran, M. H. (2013). Large panel data models with cross-sectional dependence: a survey. CAFE Research Paper, (13.15).

Dickey, D. A., \& Fuller, W. A. (1981). Likelihood ratio statistics for autoregressive time series with a unit root. Econometrica: journal of the Econometric Society, 1057-1072.

Dumitrescu, E.-I., \& Hurlin, C. (2012). Testing for granger non-causality in heterogeneous panels. Economic Modelling, 29(4), 1450-1460.

Eberhardt, M., \& Bond, S. (2009). Cross-section dependence in nonstationary panel models: a novel estimator.

Eberhardt, M., \& Teal, F. (2010). Productivity Analysis in Global Manufacturing Production.

Fang, Z., Huang, B., \& Yang, Z. (2018). Trade openness and the environmental Kuznets Curve: Evidence from Cities in the People's Republic of China.

Fotourehchi, Z. (2017). Clean energy consumption and economic growth: A case study for developing countries. International Journal of Energy Economics and Policy, 7(2).

López, L.A., Arce, G., Zafrilla, J.E. (2013), Parcelling virtual carbón in the pollution haven hypothesis. Energy Economics, 39, 177-186.

Gani, A. (2013), The effect of trade and institutions on pollution in the Arab countries. Journal of International Trade Law and Policy, 12(2), 154-168.

Gong, W., \& razmjooy, N. (2020). A new optimization algorithm based on OCM and PCM solution through energy reserve. International Journal of Ambient Energy, 1-14.

Hossain, S. (2012). An econometric analysis for CO2 emissions, energy consumption, economic growth, foreign trade and urbanization of Japan. Low Carbon Economy, (3), $92-105$.

Im, K. S., Pesaran, M. H., \& Shin, Y. (2003). Testing for unit roots in heterogeneous panels. Journal of Econometrics, 115(1), 53-74.

Itkonen, J. V. (2012). Problems estimating the carbon Kuznets curve. Energy, 39(1), 274-280.

Johansen, S. (1988). Statistical analysis of cointegration vectors. Journal of Economic Dynamics and Control, 12(2), 231-254. 
Joo, Y. J., Kim, C. S., \& Yoo, S. H. (2015). Energy consumption, CO2 emission, and economic growth: evidence from Chile. International Journal of Green Energy, 12(5), 543-550.

Kahia, M., Jebli, M. B., \& Belloumi, M. (2019). Analysis of the impact of renewable energy consumption and economic growth on carbon dioxide emissions in 12 MENA countries. Clean Technologies and Environmental Policy, 21(4), 871-885.

Kapetanios, G., Pesaran, M. H., \& Yamagata, T. (2011). Panels with nonstationary multifactor error structures. Journal of econometrics, 160(2), 326-348.

Khan, M. K., Khan, M. I., \& Rehan, M. (2020). The relationship between energy consumption, economic growth and carbon dioxide emissions in Pakistan. Financial Innovation, 6(1), 1-13.

Khan, M. K., Khan, M. I., \& Rehan, M. (2020). The relationship between energy consumption, economic growth and carbon dioxide emissions in Pakistan. Financial Innovation, 6(1), $1-13$.

K1lavuz, E., \& Doğan, İ. (2021). Economic growth, openness, industry and CO2 modelling: are regulatory policies important in Turkish economies? International Journal of LowCarbon Technologies, 16(2), 476-487.

Kuznet, S. (1955). Economic growth and income inequality. American Economic Review, 45(1), 1-28.

Levin, A., Lin, C.-F., \& James Chu, C.-S. (2002). Unit root tests in panel data: Asymptotic and finite-sample properties. Journal of Econometrics, 108(1), 1-24.

Li, T., Wang, Y., \& Zhao, D. (2016). Environmental Kuznets curve in China: new evidence from dynamic panel analysis. Energy Policy, 91, 138-147.

Liu, X., Wang, Z., Sun, X., Zhang, L., \& Zhang, M. (2020). Clarifying the relationship among clean energy consumption, haze pollution and economic growth-based on the empirical analysis of China's Yangtze River Delta Region. Ecological Complexity, 44, 100871.

López, L.A., Arce, G., Zafrilla, J.E. (2013), Parcelling virtual carbon in the pollution haven hypothesis. Energy Economics, 39, 177-186.

Maddala, G. S., \& Wu, S. (1999). A comparative study of unit root tests with panel data and a new simple test. Oxford Bulletin of Economics and Statistics, 61(S1), 631-652.

Obradović, S., \& Lojanica, N. (2017). Energy use, CO2 emissions and economic growthcausality on a sample of SEE countries. Economic research-Ekonomska istraživanja, $30(1), 511-526$.

Osobajo, O. A., Otitoju, A., Otitoju, M. A., \& Oke, A. (2020). The Impact of Energy Consumption and Economic Growth on Carbon Dioxide Emissions. Sustainability, 12(19), 7965.

767 
Pata, U. K. (2018). Renewable energy consumption, urbanization, financial development, income and $\mathrm{CO} 2$ emissions in Turkey: testing EKC hypothesis with structural breaks. Journal of Cleaner Production, 187, 770-779.

Pedroni, P. (2001a). Fully modified OLS for heterogeneous cointegrated panels. In B. H. Baltagi (Ed.), Nonstationary panels, panel cointegration, and dynamic panels. Bingley: Emerald Group Publishing. 15, 93-130.

Pedroni, P. (2001b). Purchasing power parity tests in cointegrated panels. The Review of Economics and Statistics, 83(4), 727-731.

Pedroni, P. (2004). Panel cointegration: Asymptotic and finite sample properties of pooled time series tests with an application to the PPP hypothesis. Econometric Theory, 20(3), 597-625.

Pesaran, M. H. (2004). General diagnostic tests for cross-sectional dependence in panels. Cambridge working paper in economics, No 0435.

Pesaran, M. H. (2006). Estimation and inference in large heterogeneous panels with a multifactor error structure. Econometrica, 74(4), 967-1012.

Pesaran, M. H. (2007). A simple panel unit root test in the presence of cross-section dependence. Journal of applied econometrics, 22(2), 265-312.

Pesaran, M. H., \& Yamagata, T. (2008). Testing slope homogeneity in large panels. Journal of econometrics, 142(1), 50-93.

Pesaran, M. H., \& Smith, R. (1995). Estimating long-run relationships from dynamic heterogeneous panels. Journal of econometrics, 68(1), 79-113.

Phillips, P. C., \& Sul, D. (2003). Dynamic panel estimation and homogeneity testing under cross section dependence. The Econometrics Journal, 6(1), 217-259.

Piłatowska, M., \& Geise, A. (2021). Impact of clean energy on CO2 emissions and economic growth within the phases of renewables diffusion in selected european countries. Energies, 14(4), 812.

Ramezani, M., Bahmanyar, D., \& Razmjooy, N. (2020). A new optimal energy management strategy based on improved multi-objective antlion optimization algorithm: applications in smart home. SN Applied Sciences, 2(12), 1-17.

Rauf, A., Liu, X., Amin, W., Ozturk, I., Rehman, O. U., \& Hafeez, M. (2018). Testing EKC hypothesis with energy and sustainable development challenges: a fresh evidence from belt and road initiative economies. Environmental Science and Pollution Research, 25(32), 32066-32080.

Saliminezhad, A., \& Bahramian, P. (2020). Clean energy consumption and economic growth nexus: asymmetric time and frequency domain causality testing in China. Energy Sources, Part B: Economics, Planning, and Policy, 15(1), 1-12. 
Sarafidis, V., \& Robertson, D. (2009). On the impact of error cross-sectional dependence in short dynamic panel estimation. The Econometrics Journal, 12(1), 62-81.

Sbia, R., Shahbaz, M., \& Hamdi, H. (2014). A contribution of foreign direct investment, clean energy, trade openness, carbon emissions and economic growth to energy demand in UAE. Economic modelling, 36, 191-197.

Sharif, A., Raza, S. A., Ozturk, I., \& Afshan, S. (2019). The dynamic relationship of renewable and non-renewable energy consumption with carbon emission: A global study with the application of heterogeneous panel estimations. Renewable Energy, 133, 685-691.

Sohag, K., Taşkın, F. D., \& Malik, M. N. (2019). Green economic growth, cleaner energy and militarization: Evidence from Turkey. Resources Policy, 63, 101407.

Statistical Review of World Energy (2020), The Statistical Review of World Energy analyses data on world energy markets from the prior year. The Review has been providing timely, comprehensive and objective data to the energy community since 1952 .

Stern, D. I. (2019). Energy and economic growth. In Routledge Handbook of Energy Economics (pp. 28-46). Routledge.

Swamy, P. A. (1970). Efficient inference in a random coefficient regression model. Econometrica: Journal of the Econometric Society, 311-323.

World Bank (2020). World development indicators, World Bank. Available from https://databank.worldbank.org/reports.aspx?source=world development-indi

World Economic Forum (2012). Energy for Economic Growth Energy Vision Update 2012. Energy for Economic Growth. Retrieved from http://www3.weforum.org/docs/WEF_EN_EnergyEconomicGrowth_IndustryAgenda _2012.pdf

$\mathrm{Wu}, \mathrm{H} . \mathrm{M}$. (2020). The impact of non-clean energy consumption on economic growth: evidence from symmetric and asymmetric analyses in the US. Energy \& Environment, 31(2), 291-307.

Yao, S., Zhang, S., \& Zhang, X. (2019). Renewable energy, carbon emission and economic growth: A revised environmental Kuznets Curve perspective. Journal of Cleaner Production, 235, 1338-1352.

Zou, S., \& Zhang, T. (2020). CO2 Emissions, Energy Consumption, and Economic Growth Nexus: Evidence from 30 Provinces in China. Mathematical Problems in Engineering, 2020.

Zhang, G., Xiao, C., \& Razmjooy, N. (2020). Optimal operational strategy of hybrid PV/wind renewable energy system using homer: a case study. International Journal of Ambient Energy, 1-14. 